\title{
Increased multiple sclerosis relapses related to lower prevalence of pain
}

\author{
Aumento nos surtos de esclerose múltipla relacionado com menor prevalência de dor \\ José Vinícius Martins da Silva1, Beatriz Fátima Alves de Oliveira², Osvaldo José Moreira do Nascimento?, \\ João Gabriel Dib Farinhas', Maria Graziella Cavaliere ${ }^{3}$. Henrique de Sá Rodrigues Cal', André Palma da \\ Cunha Matta ${ }^{1}$
}

\begin{abstract}
Objective: The study aims to investigate the presence of pain amongst multiple sclerosis (MS) patients. Method: One hundred MS patients responded to questionnaires evaluating neuropathic and nociceptive pain, depression and anxiety. Statistical analysis was performed using the Mann-Whitney U, Chi-Square and two-tailed Fisher's exact tests and multivariate logistic regression. Results: Women had a statistically higher prevalence of pain $(p=0.037)$, and chances of having pain after the age of 50 reduced. Women with pain had a statistically significant lower number of relapses $(p=0.003)$, restricting analysis to those patients with more than one relapse. After the second relapse, each relapse reduced the chance of having pain by $46 \%$. Presence of pain was independent of Expanded Disability Status Scale (EDSS) anxiety, and depression. Conclusion: Our findings suggest a strong inverse association between relapses and pain indicating a possible protective role of focal inflammation in the control of pain.
\end{abstract}

Keywords: multiple sclerosis, pain, prevalence, relapses, gender.

\section{RESUMO}

Objetivo: 0 estudo tem como objetivo investigar a presença de dor entre pacientes com esclerose múltipla (EM). Método: Cem pacientes com EM responderam a questionários avaliando dor neuropática e nociceptiva, depressão e ansiedade. A análise estatística foi realizada através dos testes de Mann-Whitney U, Qui-Quadrado, two tailed Fisher exact test e regressão logística multivariada. Resultados: As mulheres apresentaram estatisticamente uma maior prevalência de dor ( $p=0,037$ ), e as chances de ter dor após a idade de 50 reduziram. As mulheres com dor tinham um número com significância estatística reduzido de surtos ( $p=0,003)$, restringindo a análise aos pacientes com mais de um surto. Após o segundo surto, cada surto reduziu a chance de ter dor em 46\%. A presença de dor foi independente da Expanded Disability Status Scale (EDSS) ansiedade e depressão. Conclusão: Nossos resultados sugerem uma forte associação inversa entre o surto e a dor, indicando um possível papel protetor da inflamação focal no controle da dor.

Palavras-chave: esclerose múltipla, dor, prevalência, surto, sexo.

While several studies have found a relationship for the development of pain related to one or more multiple sclerosis (MS) factors such as patient's age, duration of disease, disease course, and disability ${ }^{1,2,3}$, virtually an equal number have not ${ }^{4,5}$. Pain clearly has a role in the disease as its prevalence has been reported ranging up to $74 \%$ in MS outpatients $^{6}$. While research does implicate factors that may be related to pain, multivariate analyses are lacking, which leaves the issue unclear as to the role of the various risk factors in the development of pain ${ }^{6}$. The development of MS pain and its severity has implications into the general evolution of the disease which itself varies amongst the different clinical forms [relapsing-remitting- (RR), primary progressive- (PP) and secondary progressive- (SP)] as well as its gender-specific presentation.

This study investigates the prevalence and severity of pain amongst multiple variables in attempt to further elucidate the role of pain within the evolution of MS. Our goal is to evaluate these results within the context of the recent mechanisms of MS that have addressed not only gender

${ }_{1}^{1}$ Universidade Federal Fluminense, Departamento de Neurologia e Centro de Pesquisas Clínicas em Neurologia/Neurociência, Niteroi RJ, Brazil;

${ }^{2}$ Fundação Oswaldo Cruz, Escola Nacional de Saúde Pública, Rio de Janeiro RJ, Brazil;

${ }^{3}$ Universidade Federal Fluminense, Interna da Disciplina de Neurologia, Niteroi RJ, Brazil.

Correspondence: André P. C. Matta; Av. Marquês de Paraná 303; 24033-900 Niterói RJ, Brasil; E-mail: andrepcmatta@hotmail.com

Conflict of interest: There is no conflict of interest to declare.

Funding: This research was partially funded by Biogen Idec, Inc. Grant number: BRA-AVX-11-10219.

Received 06 January 2015; Received in final form 27 February 2015; Accepted 20 March 2015. 
issues but also the relationship of relapses to long term disability and the progression of RR to SP, implicating two distinct disease phases related to late outcome. We hope to provide further insight into the relationship of pain to these end-points and its possible role in the natural history of the disease.

\section{METHOD}

\section{Procedure}

In this cross-sectional clinic based study we administered a questionnaire to 100 consecutive MS patients. The questionnaire included a total of 65 questions, which included the Brazilian-portuguese validated questionnaires DN4 ${ }^{7}$ (Neuropathic Pain in 4 questions), the LANSS ${ }^{8}$ (Leeds assessment of neuropathic symptoms and signs), Beck Depression Inventory (BDI) ${ }^{9}$ and Anxiety (BAI) ${ }^{9}$, a pain questionnaire and disease related information. The survey was given to each patient at the end of their physician consult to complete independently, with no time constraints. Statistical analysis was then performed. This study was approved by the Ethics committee of the Department of Neurology at the Antonio Pedro University Hospital Fluminense Federal University in Rio de Janeiro, Brazil and obtained according to the Declaration of Helsinki. Informed consent was obtained from all patients.

\section{Study sample}

One-hundred consecutive MS patients met the inclusion and exclusion criteria at the Antonio Pedro University Hospital in the Department of Neuro-immunology. Inclusion criteria: diagnosis of multiple sclerosis (all clinical courses) based upon the McDonald's criteria ${ }^{10}$ age between 18 and 80 years old, medication possession rate $>80 \%$. Exclusion criteria: having other known neurological conditions, cancer, renal disorders, psychiatric disorder and diabetes.

\section{Pain questionnaire}

The 13 questions structured questionnaire was based on Grau-López ${ }^{3}$. This self-reported data evaluated the presence of pain; its location including head, upper extremities, lower extremities, back or generalized; its classification as constant or intermittent; its frequency (daily, more than 3 times per week, less than 3 times per week, or 1-3 times per month); presence of Lhermitte's phenomenon; types of head pain including migraine, tensional and trigeminal neuralgia; medication used for MS; medication used for pain.

\section{Classification of pain type}

Pain was classified as either neuropathic or nociceptive. Neuropathic pain was defined as having a score of 4 or greater on the DN4 or greater than 12 on the LANSS. All other pain was otherwise classified as nociceptive.

\section{Statistical analysis}

Descriptive statistics were performed to illustrate the study population demographic characteristics (gender and age) and the MS aspects (clinical form, Expanded Disability Status Scale (EDSS) medication, onset of disease and relapses) as well as the characteristics of pain (localization, type of pain, types of headache and Lhermitte's sign) and humor status (depression and anxiety). The prevalence was estimated by gender and total population. The Mann-Whitney $\mathrm{U}$ test was used to compare continuous variables between groups. The two-tailed Fisher's exact test and Chi-Square was used for categorical variable comparison. Logistic regression models were used to estimate the associations between pain and co-variables, such as gender, age (older or younger than 50 years old), EDSS, medication, clinical form, onset of disease, relapses, depression and anxiety. In the bivariate analysis, the variables associated with pain to significance level of $10 \%$ were included in the multivariate analysis to calculate adjusted estimates of Odds Ratio (OR). In multivariate analysis, the differences lower than 0.05 were accepted as significant. All statistical analyses were performed using program support language R (The R Foundation for Statistical Computing, Vienna, Austria; http://www.r-project.org) and SPSS 16.0 (SPSS Inc., Chicago, IL, USA).

\section{RESULTS}

All 100 patients met the inclusion criteria. There were three questions that were not completed by all of the patients: presence of Lhermitte's phenomenon, 83 out of 100 responded; another two individuals did not complete the BDI (98/100) and 97/100 completed the BAI.

Descriptive statistics of prevalence rates are displayed in Table 1. Most notably, men showed statistically higher EDSS than women ( $\mathrm{p}=0.008)$ with 5.4 and 3.9 , respectively. The clinical forms of MS were statistically different amongst men (PP and SP) and women (RR) ( $\mathrm{p}=0.022)$. While women had a statistically higher prevalence of pain ( $p=0.037)$, men had significantly higher scores on the DN4 $(p=0.016)$ and LANSS $(p=0.021)$, indicating greater severity in neuropathic pain (Table 1). Neither depression nor anxiety was associated with the presence of pain.

The prevalence rates and gender distribution of the type of pain experienced by those patients with pain $(n=71)$ are shown in Table 1. Within this group, men maintained their significantly higher EDSS than women $(p=0.056)$ as in the overall population. However, pain was found to be independent of EDSS (Figure 1a and 1b). There was a significant difference in the mean number of relapses and pain in females, as seen in Figure $1 \mathrm{c}$ and $d(p=0.001)$.

Upon comparing those patients under the age of 50 to those patients over the age of 50 , we observed a statistically significant difference with younger women (under the 
Table 1. Multiple sclerosis (MS) patients characteristics stratified by gender.

\begin{tabular}{|c|c|c|c|c|c|}
\hline & \multicolumn{4}{|c|}{ Total N (with pain) } & \multirow{2}{*}{$\mathrm{p}$-value } \\
\hline & Male & Female & Total & $p$-value & \\
\hline Number of participants & $24(13)$ & $76(58)$ & $100(71)$ & 0.037 & \\
\hline Age (Mean \pm SD) & $44 \pm 11(46 \pm 14)$ & $45 \pm 12(44 \pm 12)$ & $45 \pm 12(45 \pm 12)$ & 0.942 & 0.225 \\
\hline$<50$ yo & $13(4)$ & $52(41)$ & $65(45)$ & 0.202 & 0.009 \\
\hline$\geq 50$ yo & $11(9)$ & $24(17)$ & $35(26)$ & & \\
\hline EDSS (Mean \pm SD) & $5.4 \pm 2(5.3 \pm 2)$ & $3.9 \pm 2(3.8 \pm 2)$ & $4.2 \pm 2(4.1 \pm 2)$ & 0.008 & 0.056 \\
\hline Onset of disease (Mean \pm SD) & $12 \pm 6(11 \pm 6)$ & $11 \pm 9(11 \pm 9)$ & $11 \pm 8(11 \pm 9)$ & 0.187 & 0.307 \\
\hline Relapses (Mean \pm SD) & $3.1 \pm 2(2.8 \pm 2)$ & $2.8 \pm 1(2.5 \pm 1)$ & $2.8 \pm 1(2.5 \pm 1)$ & 0.540 & 0.811 \\
\hline \multicolumn{6}{|l|}{ Clinical form: } \\
\hline PP & $5(4)$ & $8(8)$ & $13(12)$ & 0.022 & 0.022 \\
\hline $\mathrm{RR}$ & $13(6)$ & $60(46)$ & $73(52)$ & & \\
\hline SP & $6(3)$ & $5(2)$ & $11(5)$ & & \\
\hline PR & - & $3(2)$ & $3(2)$ & & \\
\hline \multicolumn{6}{|l|}{ Medication: } \\
\hline None & $6(5)$ & $10(8)$ & $16(13)$ & 0.279 & 0.067 \\
\hline Interferon & $11(3)$ & $37(27)$ & $48(30)$ & & \\
\hline Fingolimod & $2(2)$ & $4(3)$ & $6(5)$ & & \\
\hline Solumedrol & $5(3)$ & $15(10)$ & $20(13)$ & & \\
\hline Glatiramer & - & $10(10)$ & $10(10)$ & & \\
\hline Depressionb(Mean \pm SD) & $12 \pm 9(9 \pm 6)$ & $12 \pm 12(14 \pm 9)$ & $12 \pm 8(13 \pm 8)$ & 0.836 & 0.800 \\
\hline Yes & $13(9)$ & $40(32)$ & $53(41)$ & 0.992 & 0.354 \\
\hline Anxietyc (Mean \pm SD) & $11 \pm 8(10 \pm 6)$ & $16 \pm 16(14 \pm 9)$ & $15 \pm 8(13 \pm 8)$ & 0.182 & 0.087 \\
\hline Yes & $17(8)$ & $63(49)$ & $80(41)$ & 0.154 & 0.041 \\
\hline \multicolumn{6}{|l|}{ Pain types: } \\
\hline Nociceptive & 9 & 47 & 56 & 0.079 & - \\
\hline Neuropathic & 4 & 11 & 15 & & - \\
\hline \multicolumn{6}{|l|}{ Mean \pm SD: } \\
\hline DN4 & $2.8 \pm 2.1$ & $1.5 \pm 2.2$ & $1.8 \pm 2.2$ & - & 0.016 \\
\hline LANSS & $6.6 \pm 5.5$ & $4.0 \pm 5.9$ & $4.5 \pm 5.9$ & - & 0.021 \\
\hline Lhermitte's phenomenon & 9 & 22 & 31 & 0.136 & - \\
\hline \multicolumn{6}{|l|}{ Location of pain: } \\
\hline Back & 4 & 14 & 18 & & \\
\hline Extremities & 3 & 6 & 9 & 0.399 & 0.751 \\
\hline Head & 4 & 17 & 21 & & \\
\hline General & - & 1 & 1 & & \\
\hline Extremities / Back & 1 & 7 & 8 & & \\
\hline Head / Back & 0 & 7 & 7 & & \\
\hline Extremities / Head & 1 & 6 & 7 & & \\
\hline Headache types: & 5 & 30 & 35 & 0.141 & - \\
\hline Migraine & - & 9 & 9 & 0.063 & - \\
\hline Tension & 2 & 17 & 19 & & - \\
\hline Trigeminal neuralgia & 2 & 2 & 4 & & - \\
\hline
\end{tabular}

age of 50) having a higher prevalence of pain than men and older women, whereas older men (over the age of 50) had a higher prevalence of pain than women and younger men. These results are illustrated in Figure 2.

Logistical regression analysis found that females had a 2.7 greater chance of having pain than men (95\%CI: 1.04-7) and older than 50 had only a minimal affect, 1.3 greater chance of having pain than not (95\%CI: 1.07-3.2). Clinical forms showed no difference other than SP MS patients have a $67 \%$ lower risk of having pain than PP (95\%CI: 0.09-1.2). However, the most indicative factor predicting the development of pain was a lower absolute number of relapses, instead of the annualized relapse rate. Excluding those with only one relapse (13/16 having PP), each relapse after the second reduced in $46 \%$ the chance of experiencing pain [OR 0.54 (95\%CI:0.33-0.88)] adjusted for age and sex, but there was an interaction between sex and age as demonstrated in Table 2 - Model 1 and 2 ; this was found to be independent of relapse rate as shown in Figure 3, which demonstrates the number of relapses by pain (yes or no) and by medication/treatment type. Besides, 

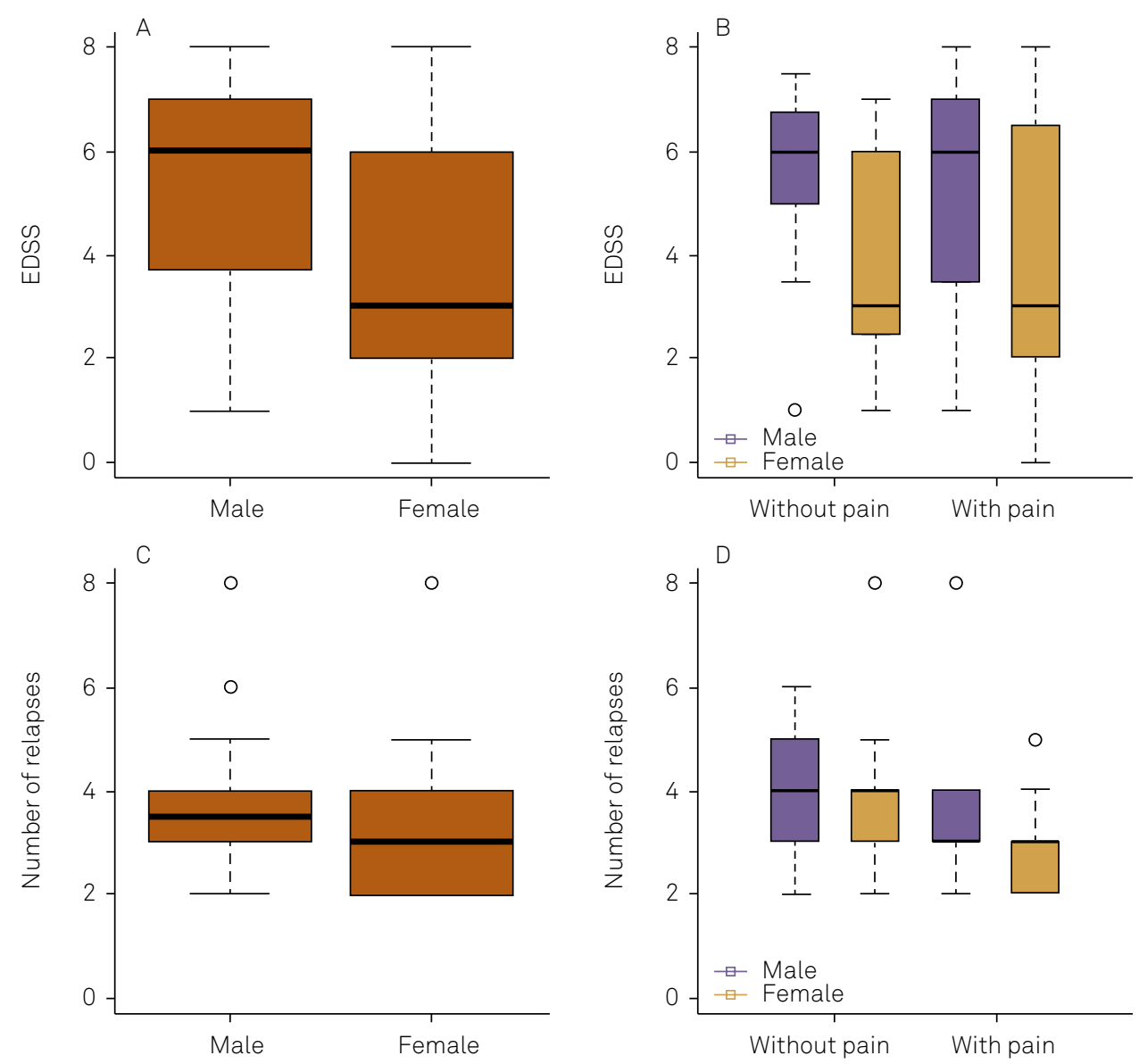

Figure 1. (A) Difference of average Expanded Disability Status Scale (EDSS) by gender ( $p$-value = 0.008); (B) Difference of average EDSS by gender in subjects with pain ( $p$-value $=0.056$ ) and without pain ( $p$-value $=0.045)$. Difference of average EDSS by pain in subjects male $(p$-value $=0.814)$ and in female $(p$-value $=0.843)$; $(C)$ Difference of average relapse number by gender ( $p$-value $=0.048)$; (D) Difference of average relapse number by gender in subjects with pain ( $p$-value $=0.120)$ and without pain $(p$-value $=0.780)$. Difference of average relapse number by pain in subjects' male ( $p$-value $=0.491)$ and in female $(p$-value $=0.003)$.

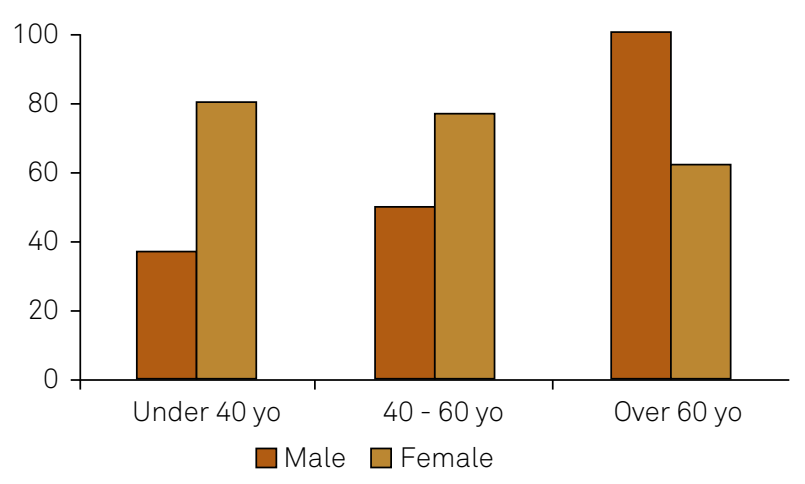

This figure represents model 2 of logistic regression model supporting the age-related benchmarks and change of the disease and trends.

Figure 2. Differences in prevalence of "presence of pain" over age of multiple sclerosis (MS) patients, stratified by gender.

no statistical relationship was found between different medications. The complete results from the logistical analysis are demonstrated in Table 2.

We both excluded and included those patients with one relapse, and found that our results were statistically significant in both cases. There were 16 patients with one relapse,
13 of which were diagnosed with PP, one of which was diagnosed with SP and two of which had RR, one of whom was 46 years old and was painless, another 24 years old who had pain. All those with one relapse were excluded, as we did not have the MRI data and, based upon only self-reported data, we felt that including the PP and the other three patients had a greater chance of skewing the data, as there is a chance of these three cases being either PP or a clinically isolated syndrome (CIS). PP was eliminated so the data would more clearly represent the phase 1 - relapsing phase and the impact on pain.

\section{DISCUSSION}

Our population displayed similar characteristics found in other studies, including the higher prevalence among women and prevalence of pain in general. Presence of pain was independent of EDSS and had a negative association with relapses experienced. While the tendency was seen far greater in women, we believe the causes could be due to the greater 
Table 2. Logistical regression analyses.

\begin{tabular}{|c|c|c|c|c|c|c|c|c|c|c|c|c|}
\hline & & Bivariate analys & & & Model 1 & & & Model 2 & & & Model $3^{a}$ & \\
\hline & $\beta$ & OR (95\%Cl) & $\mathrm{p}$-value & $\beta$ & OR $(95 \% \mathrm{Cl})$ & $\mathrm{p}$-value & $\beta$ & OR (95\%Cl) & $\mathrm{p}$-value & $\beta$ & OR (95\%Cl) & $\mathrm{p}$-value \\
\hline Gender & & & & & & & & & & & & \\
\hline Female & 1.0 & $2.7(1.04-71)$ & 0.004 & 2.12 & $8.4(2.17-32)$ & 0.002 & 2.2 & $9.6(2.2-40.8)$ & 0.002 & 0.72 & $2.06(0.64-6.6)$ & 0.222 \\
\hline Age & & & & & & & & & & & & \\
\hline 50 or more & 0.25 & $1.28(0.51-3.2)$ & 0.590 & 2.31 & $10(1.5-70)$ & 0.010 & 3.0 & $21.7(2.07-227)$ & 0.001 & -0.12 & $0.88(0.29-2.7)$ & 0.828 \\
\hline Gender*age & & & & & & & & & & & & \\
\hline $\begin{array}{l}\text { Female: } 50 \\
\text { or more }\end{array}$ & - & - & - & -2.7 & $0.1(0.01-0.6)$ & 0.010 & -3.7 & $0.1(0.002-0.34)$ & 0.006 & - & - & - \\
\hline Clinical form: & & & & & & & & & & & & \\
\hline $\mathrm{SP}$ & -0.09 & $0.33(0.09-1.2)$ & 0.090 & - & - & - & - & - & - & - & - & - \\
\hline EDSS & -0.06 & $0.93(0.78-1.12)$ & 0.480 & - & - & - & - & - & - & - & - & - \\
\hline $\begin{array}{l}\text { Onset } \\
\text { disease }\end{array}$ & -0.02 & $0.98(0.93-1.03)$ & 0.460 & - & - & - & - & - & - & - & - & - \\
\hline Relapses & -0.54 & $0.57(0.4-0.83)$ & 0.003 & & & & -0.62 & $0.5(0.36-0.79)$ & 0.001 & -0.6 & $0.54(0.33-0.88)$ & 0.014 \\
\hline $\begin{array}{l}\text { Lhermitte's } \\
\text { sign }\end{array}$ & 0.67 & $1.95(0.48-7.8)$ & 0.345 & - & - & - & - & - & - & - & - & - \\
\hline Depression & & & & & & & & & & & & \\
\hline Yes & 0.53 & $1.71(0.7-4.1)$ & 0.240 & - & - & - & - & - & - & - & - & - \\
\hline Anxiety & & & & & & & & & & & & \\
\hline Yes & 0.13 & $1.14(0.4-3.4)$ & 0.808 & - & - & - & - & - & - & - & - & - \\
\hline
\end{tabular}

number of women in our study or a gender or sex-related explanation. Though it should be noted that men showed the same trends found among women when stratified in a similar representation as showed in Figure 4, we grouped together the sexes as the sample size is limited. Our exclusion of PP and the three cases with one relapse was to attempt to eliminate any element of confounding that could be caused by patients that may be misdiagnosed with RR-MS rather than a CIS or PP. While the statistical significance in our finding was present whether we included or excluded PP, we felt that the inclusion of PP may too strongly influence the results and as such it remained excluded from our analysis. Our results were unexpected, yet not completely out of the realm of reason and had strong support in recent MS literature. Nevertheless, we have done our due diligence in our statistical analysis, data collection, recording and interpretation to state with certainty our findings and have tried to account for any confound or aspect of the disease that may have been overlooked and that would provide an alternative hypothesis. Of course, there are always factors that cannot be controlled and should be considered when relying upon self-reported data from patients, which answers may be exaggerated and present biases such as social desirability or suggestion. We have no evidence of such a bias in our study and attempted to use the DN4, LANSS, BAI and BDI to assist in this error.

The incidence of RR-MS has been close to 2-3 times greater for women than for men, whereas the PP is a 1:1 ratio. While incidence of RR has been predominantly associated with women, severity of the disease has been linked to men. As such, the role of this gender bias has typically been considered in congruous with relapses occurring more in women than in men, though men being more severe. However, with recent studies on disability and disease progression invalidating the long held belief that relapses were indicative or related to disease/disability progression or severity, questions as to the role of relapses in MS or this first relapsing phase within the natural progression of the disease have been raised.

Our results propose that relapses are related to diminished prevalence of pain, suggesting that the first relapsing phase of MS may be protective against pain in the underlying second phase which appears to be more age-related ${ }^{3,11,12,13,14}$. This would imply that the increase in relapses that women undergo in their premenstrual cycle ${ }^{15}$, postpartum period ${ }^{16}$ and assisted reproductive technology (ART) with gonadotropin releasing hormone agonists ${ }^{17}$ are all indicative of the female sex related hormones/genes causing increased relapses and their surrogate lesions as a possible "protective" function by reducing pain-related brain activation in anticipation of the underlying "dormant" disease (second phase) when more debilitating progression will occur. This would also clarify the reason that more severe disability is found in men early on and greater prevalence of pain in the second phase of the disease, as it is exposure to female steroid hormones that increases the susceptibility for relapses ${ }^{12}$. Unfortunately, our finding remain speculative as we have found few studies on pain in multiple sclerosis and none that have stratified based upon sex.

While MRI analysis and lesion load is beyond the scope of our study, MRI $\mathrm{T}_{2}$ or gadolinium enhancing lesions have 


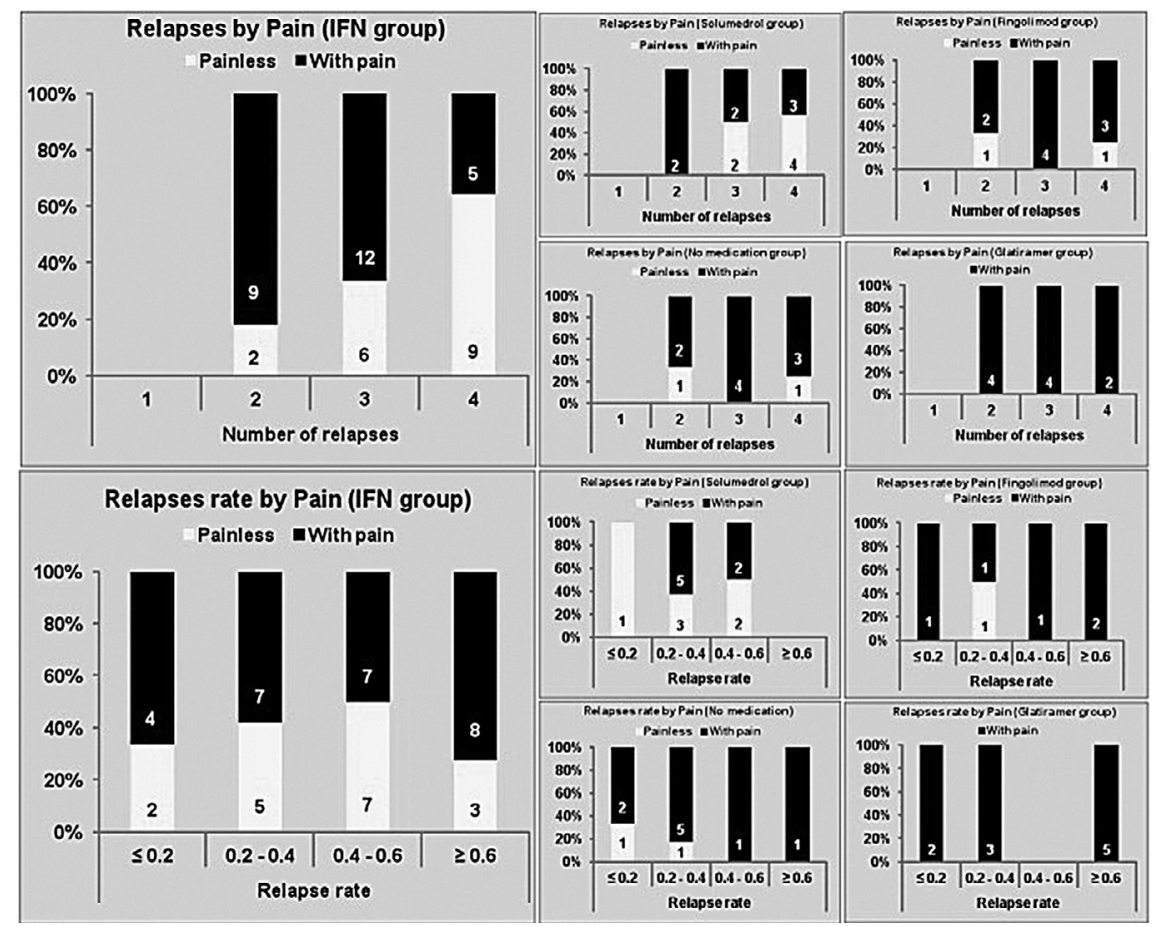

A representation of our population by those with and without pain stratified by number of relapses and by medication use. There was no difference amongst the use of medication as the $\mathrm{N}$ was very small in most cases. As the first line treatment in our clinic is Interferon, we have highlighted to represent better the trend that our results demonstrate. The $\mathrm{N}$ is represented at the base of each group.

Figure 3. Pain/Painless by number of relapses and medication use.

long been established as the surrogates of focal inflammation $^{18}$. Even though pain has been associated with various pain syndromes in MS (i.e. extremity pain, back pain, etc.), there has not been an association found between pain and the site of demyelination ${ }^{19}$ though it has been associated with depression, spinal cord involvement at the onset and the presence of spinal cord lesions ${ }^{3}$. The damage to the pain pathways has been theorized to possibly involve glia and cytokines ${ }^{20}$, which has been linked to the possible mechanism of central pain ${ }^{21}$. However, no significant pain relief has been found with any of the disease modifying medications that target the immune system. Furthermore, our results are supported by recent work in neuroimaging, which suggests that intrinsic brain connectivity is associated with chronic pain intensity ${ }^{22}$, implying that lesions or demyelinating neurodegeneration may reduce or eliminate pain sensation. This concept directly contradicts the formerly held belief of the role of relapses and supports other work in Neurology which proposes that pain is a multimodal evaluative or distributed process in the brain ${ }^{22}$. Recent studies investigating brain lesions support the hypothesis that they may serve as a function of the body to reduce pain-related cortical activity ${ }^{23}$, or the sensory-discriminative processing of pain ${ }^{23}$ meanwhile maintaining intact tactile thresholds ${ }^{23}$ thus serving as a protective measure against pain or aid in its tolerability.

We postulate that with the increase of lesion load, associated with a higher number of relapses, it is possible that the interpretation of painful stimuli by the brain is impaired or that the arrival of those stimuli to somatosensorial pathways is decreased. One study ${ }^{24}$ found that, in a long-term basis, accumulation of relapses and their consequences are less evident in patients with MS. Furthermore, with the advent of more powerful MRI scans, the confirmation of involvement of the gray matter became more sensitive. Harrison et $\mathrm{al}^{25}$ conducted a study with 34 patients and demonstrated through 7-Tesla MRI scan that thalamic lesions were present in 24 patients. It is known that such lesions are associated with a higher EDSS score, cortical lesions and progressive forms. Regarding the thalamus as a major relay of pain, its involvement in patients with MS diminish the arrival of nociceptive inputs to cortical regions.

Studies of pain in MS patients have attempted to link the location of lesions to related pain and have found difficulty in defending this theory. For example, ongoing extremity pain is more common in patients with primary progressive or the progressive-relapsing (PR) types of MS, and lowest in the RR type ${ }^{26}$. MRI studies usually show plaques in the cervical and thoracic spinal cord, however the bilateral and relatively distal distribution is difficult to explain as there is ample evidence that excludes peripheral nerve involvement ${ }^{5}$. MS-related trigeminal neuralgia (TN) has long been attributed to a demyelinating plaque in the pons, as seen in postmortem specimens ${ }^{27}$, however this contrasts with the frequent neuroimaging finding of a neurovascular contact with the trigeminal root in patients with TN and MS and the existence of some patients with MS who have $\mathrm{TN}$ as the sole clinical manifestation and the microvascular decompression outcome of neurosurgical studies results in 


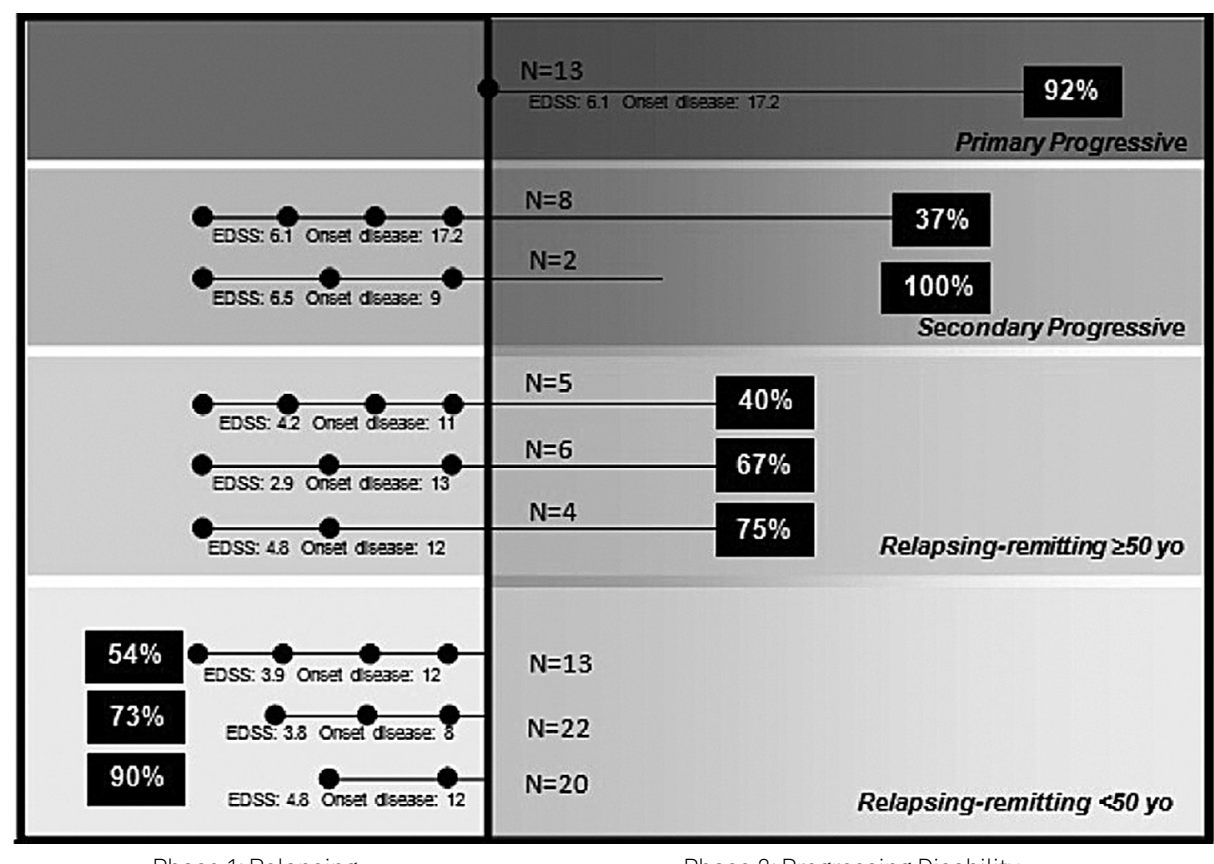

Phase 1: Relapsing

Phase 2: Progressing Disability

The percentage of multiple sclerosis (MS) patients with pain is represented in the black boxes per phase. This model presents that relapsing-remitting patients over the age of 50 represent individuals who are in the second stage based upon age (as is separated in the lower two boxes). The points on the line represent corresponds to number of relapses experience by these patients, with the sub group Expanded Disability Status Scale (EDSS) and average onset of disease listed below. The $\mathrm{N}$ of each subgroup is listed. When stratified by gender, we found similar trends between the representations but as our population size is limited, both genders are represented in this figure.

Figure 4. Representation of our results in the two-phase disease model proposed by Leray ${ }^{28}$.

considerable pain relief ${ }^{27}$. Lhermitte's phenomenon, which is thought to come from a demyelinating plaque in the dorsal columns at the cervical level, is for many patients a transient symptom, manifesting for some weeks then resolving spontaneously ${ }^{26}$. Painful tonic spasms are more MS-specific. They are involuntary muscle contractions that last less than 2 minutes sometimes several times per day and usually continue for weeks or months and then disappear. They are more common in PP and SP forms and are positively correlated with age, disease duration, and disability ${ }^{26}$, although never found to be linked to relapses and appear to be linked to the second phase of MS.

Inasmuch as our study may provide a drastic shift in the role of relapses, it supports the recent two distinct phase model of $\mathrm{MS}^{11,24,28}$, gender ${ }^{12}$ and age related ${ }^{29}$ findings. However, it remains difficult to interpret drug trials, as relapses have typically been an end-point and as such creates a mind-boggling task of applying these trial results to the mechanism of action of these drugs. Even so, our results concur with several well-designed trials in SP multiple sclerosis ${ }^{30}$, which showed an unrelated impact of treatments focusing on focal inflammation (frequency of relapses and MRI activity) on delaying disability progression. This implies that therapeutics focusing on these end-points rather than disability progression are actually working against the immune system to preserve the individual from later MS related pain developed in the second phase. By no means are we able to state that relapses hold a beneficial function, however our results indicate that further studies need to be done to investigate the relationship between a possibly protective role of relapses for later developed pain. As well, while we stratified our results by medication use, this is not to imply that any relationship was found in use of medication. The fact remains that our population size is extremely limited and the use of medication, pain and relapse is confounded by the specific physician choice of therapeutic treatment. Treatment choices have a variety of considerations that are unable to be stratified or listed, as they are patient specific. We stress that our results cannot be used to draw conclusion about drug treatments used and that larger longitudinal studies would be able to offer more insight. Our findings do support that the progressive phase is the core phenotype of MS, and its probability, slope, and latency should be the targets for MS treatment and investigations.

The most obvious limitation of our study is the size of our sample. While we still reached statistical significance, our findings should be verified in larger longitudinal studies and stratified per sex to verify if the same patterns exist. On this same note, as our sample was a clinic based study, it did not have an equal number of men and women, and reflects the gender bias in incidence. We believe the intensity and location of pain, though done only general in our study should be investigated in relation to the presence of MRI $\mathrm{T}_{2}$ or gadolinium enhancing lesions. Moreover, we did not perform a regression analysis adjusted for time of disease, what we believe to be a critical limitation of study, once the greater the disease duration, the higher the relapses occurrence. Our 
next step will consist of analyzing the annualized relapse rate and its relationship to pain frequency.

In our sample, 64 patients were on immunomodulatory therapy. Among those, 48 were in regular use of interferons. Taking into account the difficulty of MS patients to adhere to treatment, we included in our study only patients with medication possession rate above $80 \%$, thus avoiding a possible selection bias.

In conclusion, regardless the number of limitations of our study, it shows a statistically significant relationship between MS relapses experienced and prevalence of painless MS patients.

\section{References}

1. Solaro C, Brichetto G, Amato MP, Cocco E, Colombo B, D'Aleo G et al. The prevalence of pain in multiple sclerosis: a multicenter cross-sectional study. Neurology. 2004;63(5):919-21. http://dx.doi.org/10.1212/01.WNL.0000137047.85868.D6

2. Hadjimichael O, Kerns RD, Rizzo MA, Cutter G, Vollmer T. Persistent pain and uncomfortable sensations in persons with multiple sclerosis. Pain. 2007;127(1-2):35-41. http://dx.doi.org/10.1016/j.pain.2006.07.015

3. Grau-López L, Sierra S, Martínez-Cáceres E, Ramo-Tello C. Analysis of the pain in multiple sclerosis patients. Neurologia. 2011;26(4):208-13. http://dx.doi.org/10.1016/j.nrl.2010.07.014

4. Kalia LV, O'Connor PW. Severity of chronic pain and its relationship to quality of life in multiple sclerosis. Mult Scler. 2005;11(3):322-7. http://dx.doi.org/10.1191/1352458505ms1168oa

5. Osterberg A, Boivie J, Thuomas KA. Central pain in multiple sclerosis: prevalence and clinical characteristics. Eur J Pain. 2005;9(5):531-42. http://dx.doi.org/10.1016/j.ejpain.2004.11.005

6. Truini A, Barbanti P, Pozzilli C, Cruccu G. A mechanismbased classification of pain in multiple sclerosis. $J$ Neurol. 2013;260(2):351-67. http://dx.doi.org/10.1007/s00415-012-6579-2

7. Santos JG, Brito JO, de Andrade DC, Kaziyama VM, Ferreira KA, Souza I et al. Translation to Portuguese and validation of the Douleur Neuropathique 4 questionnaire.J Pain. 2010;11(5):484-90. http://dx.doi.org/10.1016/j.jpain.2009.09.014

8. Schestatsky P, Félix-Torres V, Chaves ML, Câmara-Ehlers B, Mucenic T, Caumo W et al. Brazilian Portuguese validation of the Leeds Assessment of Neuropathic Symptoms and Signs for patients with chronic pain. Pain Med. 2011;12(10):1544-50. http://dx.doi.org/10.1111/j.1526-4637.2011.01221.x

9. Cunha J. Manual da versão em português das escalas Beck. São Paulo: Casa do Psicólogo; 2001.

10. Polman CH, Reingold SC, Banwell B, Clanet M, Cohen JA, Filippi $M$ et al. Diagnostic criteria for multiple sclerosis: 2010 revisions to the McDonald criteria. Ann Neurol 2011;69(2):292-302. http://dx.doi.org/10.1002/ana.22366

11. Scalfari A, Neuhaus A, Degenhardt A, Rice GP, Muraro PA, Daumer $M$ et al. The natural history of multiple sclerosis: a geographically based study 10: relapses and long-term disability. Brain. 2010;133(7):1914-29. http://dx.doi.org/10.1093/brain/awq118

12. Voskuhl RR. Gender issues and multiple sclerosis. Curr Neurol Neurosci Rep. 2002;2(3):277-86. http://dx.doi.org/10.1007/s11910-002-0087-1

13. Kremenchutzky M, Rice GP, Baskerville J, Wingerchuk DM, Ebers GC. The natural history of multiple sclerosis: a geographically based study 9: observations on the progressive phase of the disease. Brain. 2006;129(3):584-94. http://dx.doi.org/10.1093/brain/awh721

14. Stankoff B, Mrejen S, Tourbah A, Fontaine B, Lyon-Caen O, Lubetzki $C$ et al. Age at onset determines the occurrence of the progressive phase of multiple sclerosis. Neurology. 2007;68(10):779-81. http://dx.doi.org/10.1212/01.wnl.0000256732.36565.4a

15. Zorgdrager A, De Keyser J. The premenstrual period and exacerbations in multiple sclerosis. Eur Neurol 2002;48(4):204-6. http://dx.doi.org/10.1159/000066166
16. Paavilainen T, Kurki T, Parkkola R, Färkkilä M, Salonen $\mathrm{O}$, Dastidar $\mathrm{P}$ et al. Magnetic resonance imaging of the brain used to detect early post-partum activation of multiple sclerosis. Eur J Neurol. 2007;14(11):1216-21. http://dx.doi.org/10.1111/j.1468-1331.2007.01927.x

17. Michel L, Foucher Y, Vukusic S, Confavreux C, Sèze J, Brassat D et al. Increased risk of multiple sclerosis relapse after in vitro fertilisation.J Neurol Neurosurg Psychiatry. 2012;83(8):796-802. http://dx.doi.org/10.1136/jnnp-2012-302235

18. Frischer JM, Bramow S, Dal-Bianco A, Lucchinetti CF, Rauschka $\mathrm{H}$, Schmidbauer $\mathrm{M}$ et al. The relation between inflammation and neurodegeneration in multiple sclerosis brains. Brain. 2009;132( 5):1175-89. http://dx.doi.org/10.1093/brain/awp070

19. Borsook D. Neurological diseases and pain. Brain. 2012;135(2):320-44. http://dx.doi.org/10.1093/brain/awr271

20. Merson TD, Binder MD, Kilpatrick TJ. Role of cytokines as mediators and regulators of microglial activity in inflammatory demyelination of the CNS. Neuromolecular Med. 2010;12(2):99-132. http://dx.doi.org/10.1007/s12017-010-8112-z

21. Graeber MB. Changing face of microglia. Science. 2010;330(6005):783-8. http://dx.doi.org/10.1126/science.1190929

22. Napadow V, LaCount L, Park K, As-Sanie S, Clauw DJ, Harris RE. Intrinsic brain connectivity in fibromyalgia is associated with chronic pain intensity. Arthritis Rheum. 2010;62(8):2545-55. http://dx.doi.org/10.1002/art.27497

23. Starr CJ, Sawaki L, Wittenberg GF, Burdette JH, Oshiro Y, Quevedo AS et al. The contribution of the putamen to sensory aspects of pain: insights from structural connectivity and brain lesions. Brain. 2011;134(7):1987-2004. http://dx.doi.org/10.1093/brain/awr117

24. Tremlett $\mathrm{H}$, Yousefi M, Devonshire V, Rieckmann P, Zhao Y. Impact of multiple sclerosis relapses on progression diminishes with time. Neurology. 2009;73(20):1616-23. http://dx.doi.org/10.1212/WNL.0b013e3181c1e44f

25. Harrison DM, Oh J, Roy S, Wood ET, Whetstone A, Seigo MA et al. Thalamic lesions in multiple sclerosis by 7T MRI: clinical implications and relationship to cortical pathology. Mult Scler. 2015 [Forthcoming].

26. Nurmikko TJ, Gupta S, Maclver K. Multiple sclerosis-related central pain disorders. Curr Pain Headache Rep. 2010;14(3):189-95. http://dx.doi.org/10.1007/s11916-010-0108-8

27. Athanasiou TC, Patel NK, Renowden SA, Coakham HB. Some patients with multiple sclerosis have neurovascular compression causing their trigeminal neuralgia and can be treated effectively with MVD: report of five cases. Br J Neurosurg. 2005;19(6):463-8. http://dx.doi.org/10.1080/02688690500495067

28. Leray E, Yaouanq J, Le Page E, Coustans M, Laplaud D, Oger J et al. Evidence for a two-stage disability progression in multiple sclerosis. Brain. 2010;133(7):1900-13. http://dx.doi.org/10.1093/brain/awq076

29. Confavreux $C$, Vukusic $S$. Age at disability milestones in multiple sclerosis. Brain. 2006;129(3):595-605. http://dx.doi.org/10.1093/brain/awh714

30. Rice GP, Filippi M, Comi G. Cladribine and progressive MS: clinical and MRI outcomes of a multicenter controlled trial. Neurology. 2000;54(5):1145-55. http://dx.doi.org/10.1212/WNL.54.5.1145 